\title{
Buckling analysis of reinforced composite plates with a multiwall carbon nanotube (MWCNT)
}

\author{
Thaier J. Ntayeesh ${ }^{1}$, Mahmud Rasheed Ismail ${ }^{2}$ and Raed G. Saihood ${ }^{1}$ \\ ${ }^{1}$ Mechanical Engineering Department, College of Engineering, University of Baghdad, Iraq \\ ${ }^{2}$ Prosthetics and Orthotics Engineering Department, College of Engineering, Al-Nahrain University, Iraq
}

\section{Article Info}

Received Jan 18, 2019

\section{Keyword:}

Buckling of plate

Nano tube

Composite materials

Critical load

\begin{abstract}
Buckling analysis of mechanical structures is essential to insure stability under loading .Critical load of buckling refer to the maximum load can be withstood without losing of stability and avoid a catastrophic damage due to the collapse of columns .Improving of mechanical properties spatially those related with elastic behaviors of materials can lead to improving buckling since it can be raised the value of critical load . Nanotechnology is one of the modern methods which makes significant effects on the mechanical properties of materials. In the field of composite materials this technology leads to valuable improvements for the favorite properties. In this regard Nano composite materials are paid a spatial attention in research for the last decade. The main aim of the present work is to investigate the effect of Nano carbon weight fraction on buckling of the composite plate. Five samples of Nano composite plates were prepared and fabricated for experimental investigations .The plate samples are combined of woven reinforcement fiber and polyester matrix with Carbon .The weight fraction of Nano additives are $0 \%, 0.5 \%$, $1 \%, 1.5$ and $2 \%$, of resin materials weight. To provide homogenous composite an ultrasonic homogenizer is utilized. The experimental work include buckling test for different Nano plates samples with simply supported at two ends and free at the other .Finite Element analysis was achieved via ANSYS R15.0 with proper elements ,meshing ,boundary condition and static analysis .It is found that increasing of Nano carbon weight ratio tends to increase critical load of buckling ,the maximum buckling load is at $2 \% \mathrm{wt}$ ratio and the experimental results shows fair validation for the numerical analysis where the maximum error dos not exceeded $15 \%$.
\end{abstract}

\section{Corresponding Author:}

Thaier J. Ntayeesh

Mechanical Engineering Department,

College of Engineering,

University of Baghdad, Iraq

Email: thaier-aljabbery@ coeng.uobaghdad.edu.iq

\section{Introduction}

Nano composite plate reinforced by carbon fiber woven is a new trend of composite materials technology. It gains the advantage of high tensile strength, corrosion resistance, high conductivity, and high temperature resistance. Many researchers investigate the behavior of Nano composite, in this regard. 
Yas and Samadi ,2012,[1] studied buckling analysis and vibrations of Nano composite beam according to Timoshenko theory. the beam is reinforced by nanotubes (SWCNTs) and seated elastic foundation. In this work Many parameters were studied such as the fraction volume, effect of elastic foundation and slenderness. They found that these factors are very essential in the free vibrations and buckling behavior of the studied structure.

Wanga et.al.,2016 [2] proposed Galerkin method to investigate the vibration and buckling of composite plates with thin carbon reinforced with nanotube using plate theory. The buckling loads and natural frequencies of the plates at different boundary conditions were investigated.

Malekzadeh and Shojaee,2013 [3] investigated buckling behavior of laminated plates. The plate is quadrilateral and is thin to middle thickness and composed of bonded carbon layer nanotube reinforced composite. They proposed analytical solution for buckling stability and considered four types of profiles of the walled carbon nanotubes that distribution along the layers thickness. The research included an investigation of the influence of carbon nanotubes volume fraction, geometry, ratio of thickness to length, and end fixing conditions on the buckling load for the laminated plates.

Yas, and Samadi,2012 [4] stuided buckling of a functionally graded Nano composite plate. The plate is reinforced by aligned straight single walled carbon nanotubes and subjected to two types of loading. They attempted a numerical analysis to investigate the effect of the different types of compressive loadings, volume fractions to study their effects on the critical load of buckling.

Rahaman and M. Imran,2017 [5] investigated the mechanical and thermal behavior of the glass fiberepoxy and glass fiber CNT epoxy by using dynamical analysis and flexural bending test. They fabricated glass fiber einforced laminates with the epoxy matrix. The manufacturing was performed with vacuum. They used $0.5 \mathrm{wt} \% \mathrm{NH} 2$ functionalized MWCNT epoxy as a matrix.

Rahman et.al. 2015 [6] prepared a composite consisted of nanotubes with woven glass fiber with Multi walled carbon (CNTs) and epoxy as a matrix to investigate the effect of toughness due to in situ growth of CNTs on the surface of the glass fiber. They introduced thermal analysis and showed an increase in both thermal stability and glass transition of CNTs epoxy composite as compared with the baseline composite materials. They concluded that both mechanical and thermal behavior depend on fiber/matrix and the stress transfer.

Shams and Soltani 2017[7] study the influence of aspect ratio and waviness on the buckling characteristics of composite plate composed of functionally graded carbon nanotube reinforced and loaded in plane. They used reproducing kernel particle technique. They showed that these two parameters have significant effects on buckling of carbon of the studded sample plates.

Yengejeh et.al.2018[8] made a comprehensive review for the most valuable and recent studies related to Nano composite .They presented and explore the mechanical behavior for different types of reinforced carbon nanotubes. The study includes experimental and theoretical works involved in this field.

Nitin Muralidharan et.al. 2018[9] verified the multifunctional synergy between properties in a composite material exhibiting simultaneous mechanical and energy storage properties. They showed that simultaneous mechanical and electrochemical functionality with invariant and stable super capacitor performance maintained throughout the elastic regime.

Sun-Kuk Kim et.al.2012[10] fabricated and tested hybrid composite plate laminates with epoxy and carbon fiber. The plate is reinforced with carbon nanotubes (MWCNTs). They observed a better improvement in the initial decomposition and glass transition temperature of the epoxy as it reinforced with $0.5 \mathrm{wt} \%$.

In this study they observed that the stability of the composite is highly improved, however there is no effect on the tensile behavior. In the present work MWCNT composite plate with different weight of Nano carbon tubes are fabricated, tested and numerically analyzed to investigate their effect on critical load of buckling. 


\section{Experimental Investigation}

\section{Preparing of models}

The following procedure were followed for fabrication the tested samples;

1-A gypsum template is fabricated for molding process.

2-The resin is mixed with Nano particles for different weight ratio by using Ultrasonic ultra-sonic Homogenizer.

3-Nano composite plates were molded and fabricated with the aid of vacuumed machine.

4-Finally: the desired dimensions were cut using electric cutter.

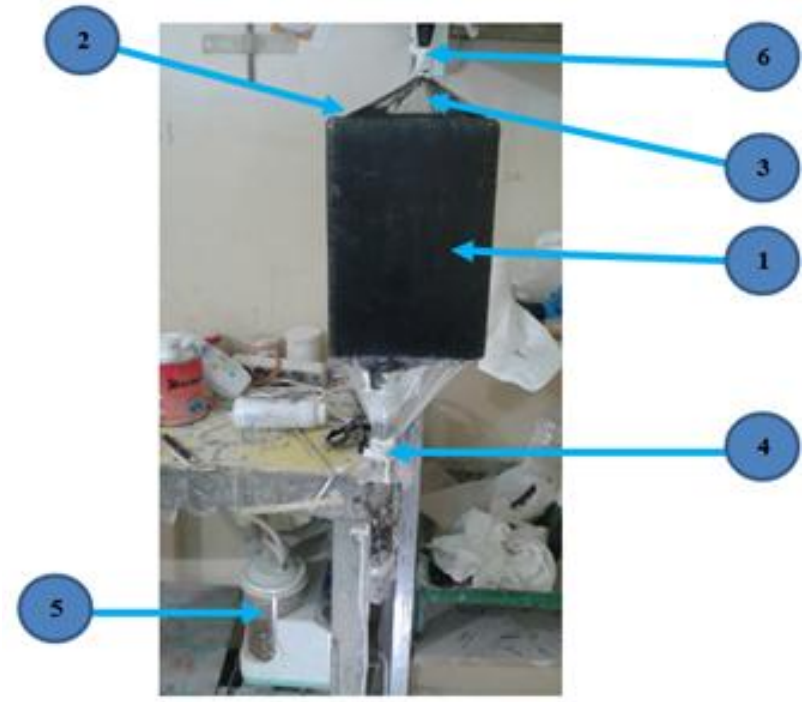

Figure-1. Embossing gypsum templates coating with woven carbon fabric.

1) Gypsum template coated with woven fiber glass, 2) Vacuum Bag (PVA),

3) Rein inside of PVA, 4) Metalic vacuum pipe, 5)Vacuum machine, 6) Input resin place.

A gypsum template with dimensions $(26 \mathrm{~cm} \times 17 \mathrm{~cm})$ for each side is used. The gypsum template is placed on the metallic vacuum pipe as shown in Figure-1, A smooth curved surface which obtained from gypsum template was inserted in a bag of PVA to isolate gypsum of template from the interaction between woven carbon sheets and resin. The bag was inserted into the vacuum process by closing it tightly from both top and bottom sides.

Ultra-sonication process is used to mix Nano particles with the resin .Ultrasonic Homogenizer (300VT) is used in the present work as shown in Figure-2. It is multi-function and multi-purpose instruments that utilize strong super sound to induce cavitation effect in liquid. It powered by the single-phase of 220VAC, $50 \mathrm{~Hz}$.It produces alternating current with of $20-25 \mathrm{kHz}$ frequency and $600 \mathrm{~V}$. Accordingly, vibrational wave induces cavitation effect by titanium lever immerged in the sample solution, to break cells and provide homogenous solution.

The Nano to resin ratios are $0.5,1,1.5$, and $2 \%$ of Multi-Walled Carbon Nanotubes (MWCNTs), with outside side diameter (6-9) $\mathrm{nm}$ and length of tube $5 \mu \mathrm{m}$ (O.D. $=6-9 \mathrm{~nm} \& \mathrm{~L}=5 \mu \mathrm{m})$ as a filler in addition to woven fabric to reinforced the lamination 80:20 resin, then the mixture are mixing homogeneously, with equal period of processing time about 20-30 minutes and taking about 5-10 minutes for rest to avoid the rise of the mixture temperature to more than $80 \mathrm{oc}$.Cooling water was used to maintain low temperature of mixture to avoid bonds break of resin.

The rapid vibration of the probe tip causes cavitation After 15 minutes, which formulated of black bubbles. The collapse of cavitation bubbles releases energy in the cavitation field which in turn increases the temperature of the mixture. It is not permitted to stop process until achieving the homogeneity of the mixture. 


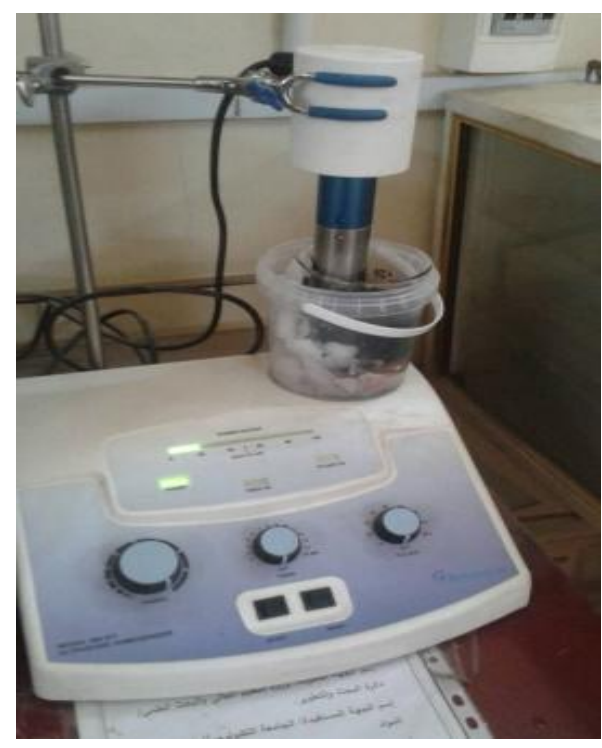

Figure-2. Ultrasonic Homogenizer (300VT)

To fabricate the composite plates the template was coated by a layer with $(26 \mathrm{~cm} \mathrm{x} 17 \mathrm{~cm})$ of woven fiber glass rectangular sheets while the remainder of the woven fiber glass was rolled into the back of the mold and governs at the back with adhesive tape.

This process is repeated for each layer until the staking of woven fiber glass sheets complete. As shown in Figure-3. The resin was flowing inside the PVA bag from the top. The vacuum device was switched on before coating glass sheets and after the resin mixed withhardener. It still in work until the resin pass through the woven glass fiber and begin to exit from outlet pipe and the composite materials begin to harden. A bag of PVA with the provisions of the closer from the top and bottom to avoid exiting the resin. A specimen dimension of $(26 \mathrm{~cm} \times 8.5 \mathrm{~cm})$ was cut using electrical cutter. Five specimens of different weight percentage of MWCNTs are prepared for buckling test as shown in Figure-4.
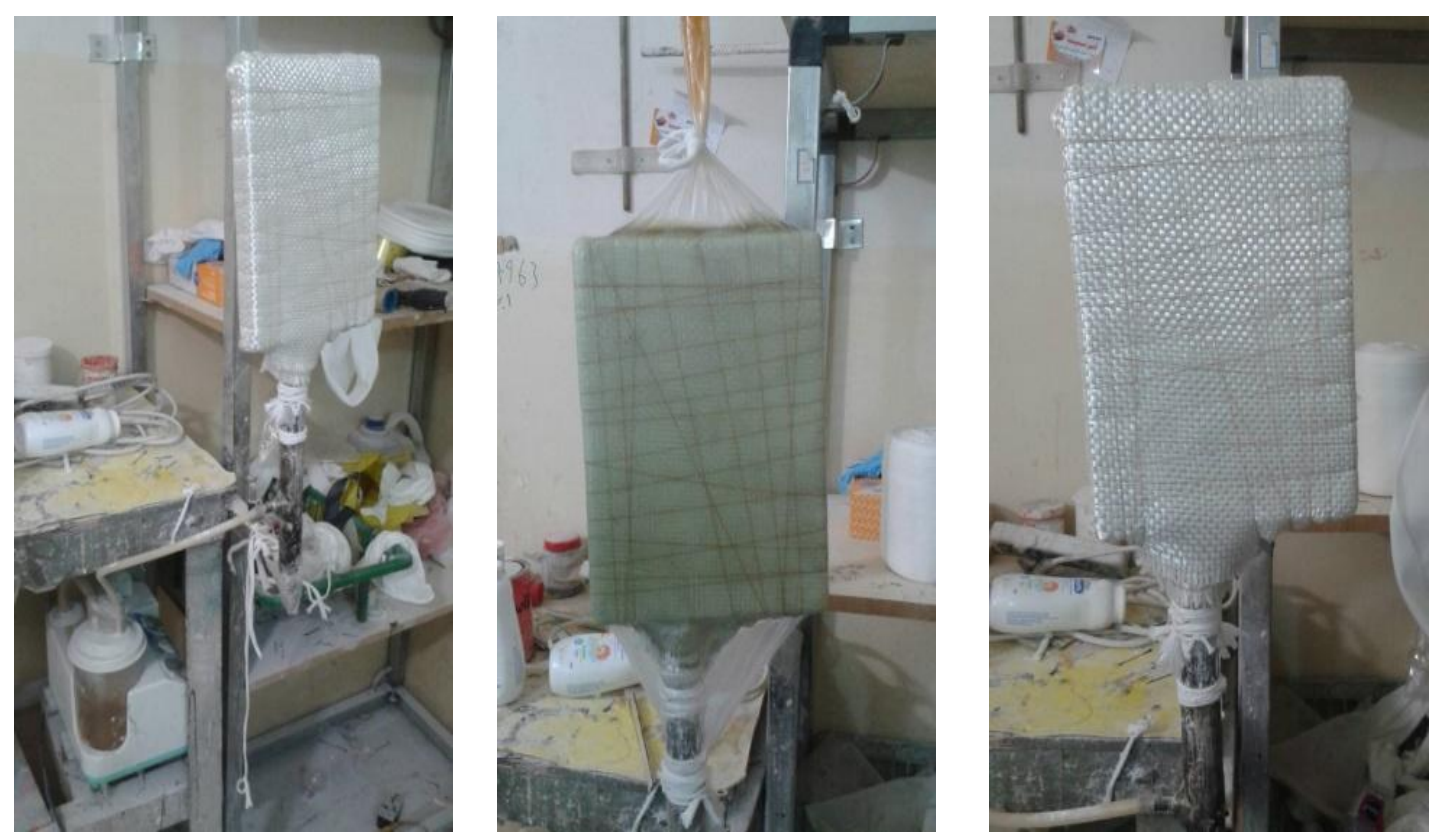

Figure-3. Fabrications of sample models 


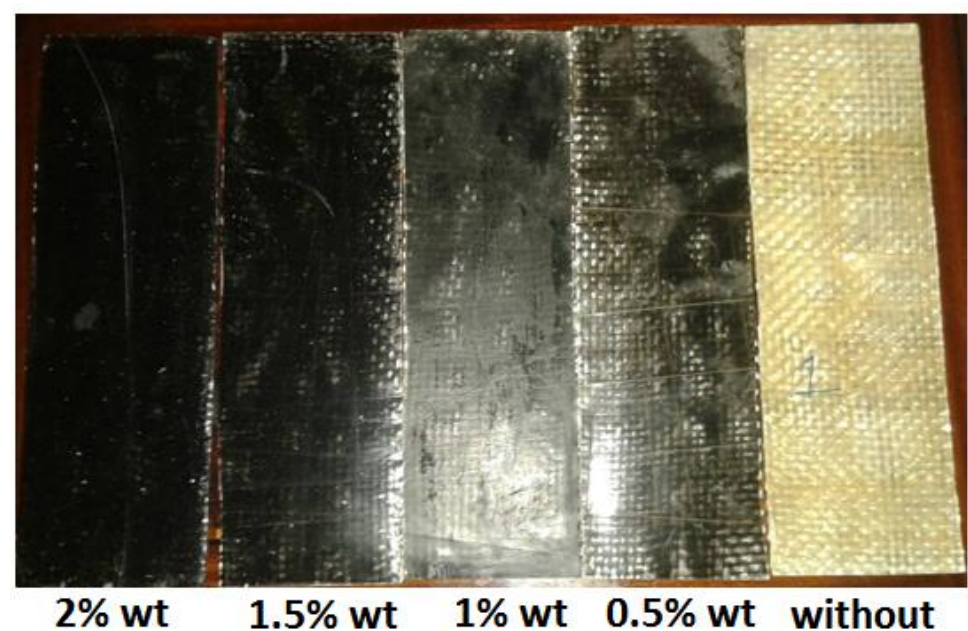

Figure-4. Composite plate reinforced with glass fiber woven with wt\% MWCNTs

\section{Measuring of elastic modulus}

Experimental of determination the elastic modulus was conducted by measuring the deflection of a fixed supported beam of the samples under applied loads. Values of the elastic modulus are obtained from calculating the slope of stress-strain line resulting from the bending test. The measuring values of modulus of elasticity for different samples are presented in Table-1.

Table-1. Modulus of elasticity of composite for composite plate samples.

\begin{tabular}{|c|c|c|}
\hline $\begin{array}{c}\text { Sample } \\
\text { NO. }\end{array}$ & \%Wt of MWCNT & Modulus of Elasticity $\mathbf{E}_{\mathbf{1}}=\mathbf{E}_{\mathbf{2}}(\mathbf{G p a})$ \\
\hline 1 & 0 & 10 \\
\hline 2 & 0.5 & 15 \\
\hline 3 & 1 & 21 \\
\hline 4 & 1.5 & 26 \\
\hline 5 & 2 & 36 \\
\hline
\end{tabular}

\section{Buckling test}

The Nano composite plate samples were loaded by axial pressure in vertical direction by using a compression test machine which capable for $100 \mathrm{KN}$ maximum loading. The plates were simply supported at both upper and lower ends and remained free at the other ends. The subjected load was gradually increasing in value until buckling existed. To accomplish simply supported conditions the plates was placed between two very stiff heads of machine and allowed to rotate freely at the supports to insure zero moment. The feeding speed of compressive loading was $2 \mathrm{~mm} / \mathrm{min}$. The experimental set up is shown in Figure-5. 

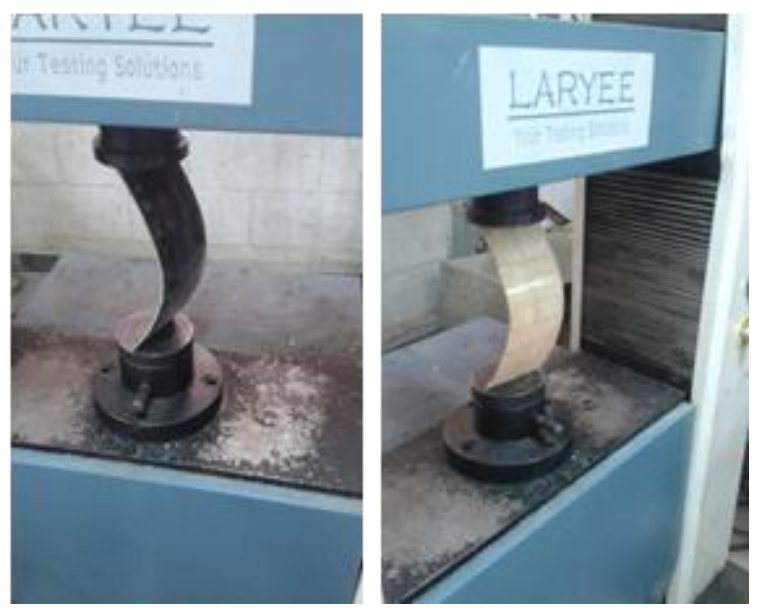

Figure-5. Buckling test of Nano composite plates.

The critical load of buckling is determined from the load-displacement curve as shown in Figure-6. Where the point that left from the straight line is determined from the graphics and the corresponding vertical coordinate represents the critical load of buckling [11].

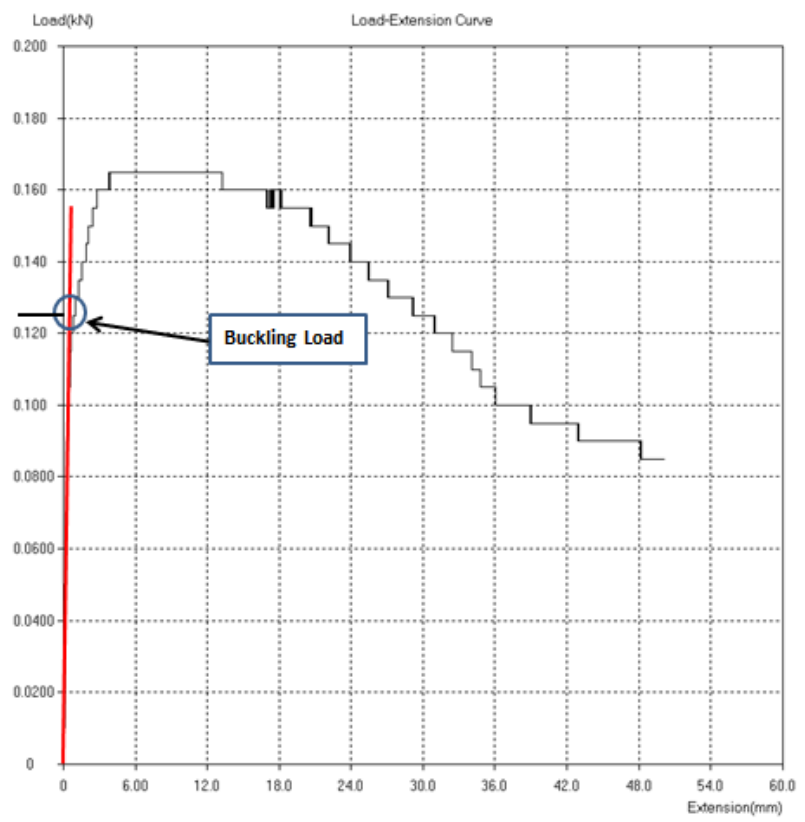

Figure-6. Load - displacement curve and buckling load.

\section{Numerical Analysis}

Finite Elements (FE) analysis represents an effective tool to analysis complicated problems such as Nano composite plate since they are anisotropic and nonhomogeneous materials. ANSYS R.15.0 software is used for the presented analysis. The geometrical modeling of structures for the samples are created in Workbench. A three dimensional SHELL181 elements type is used for FE analysis as shown in Figure-7 . It is a 4-node element with six degrees of freedom at each node; translations in $\mathrm{x}, \mathrm{y}, \mathrm{z}$ directions, and rotations about the $\mathrm{x}$, $\mathrm{y}, \mathrm{z}$ directions. Material properties such as modulus of elasticity, Poison's ratio and density are assigned for each element. 


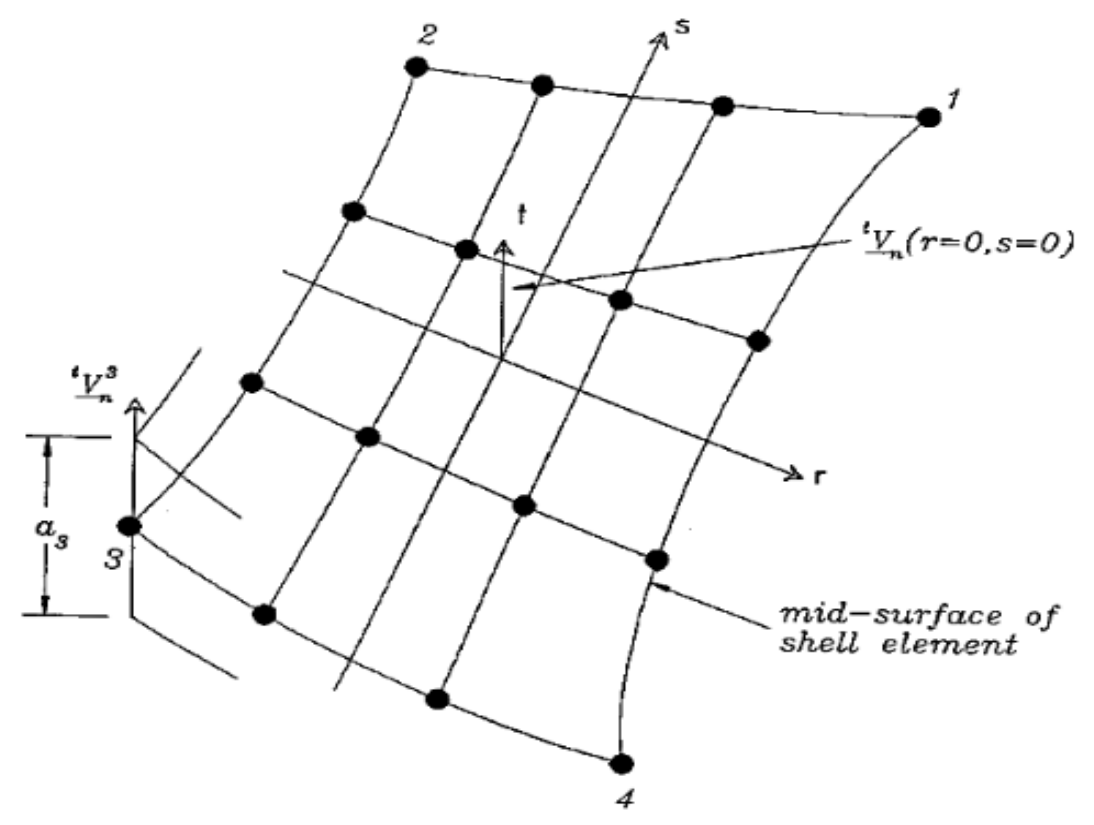

Figure-7. Shell element.

The sample models are then meshed. Meshing is generated automatically by selecting mapped face meshing with different level of precision. size, shape and refinement of the mesh is controlled, as shown in Figure-8. The size and shape of the meshes should be selected carefully, since it affects the accuracy of results.

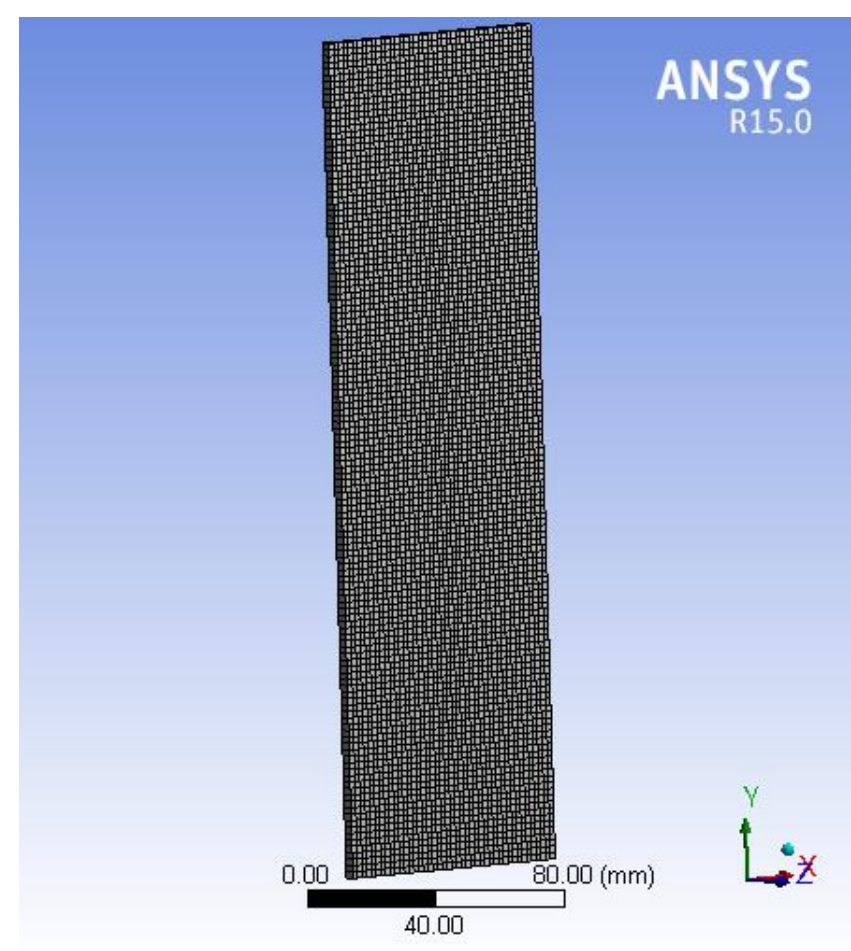

Figure-8. Model meshing.

To specify the boundary conditions of the models the top and bottom end are fixed in all DOF and the other ends are free. Pressure is applied on the top surface as well as the interior with a magnitude of $2 \mathrm{MPa}$ as shown in Figure-9. 


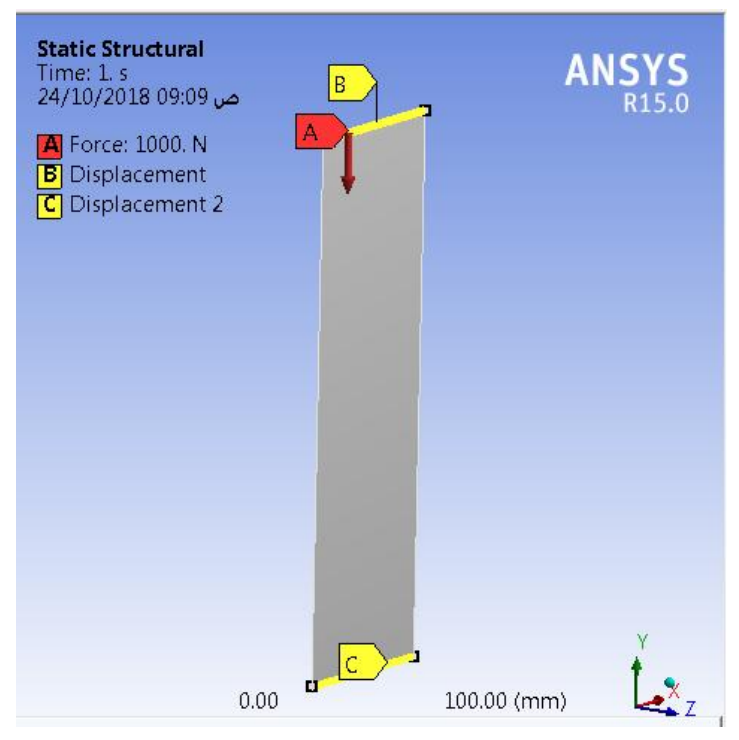

Figure-9. Load and boundary conditions.

Finally ; Static analysis and buckling analysis were performed to calculate the critical load and deformations then the analysis of linear buckling analyses is carried out and the eigenvalues and buckling shape patterns are evaluated for each model as shown in Figure-10.

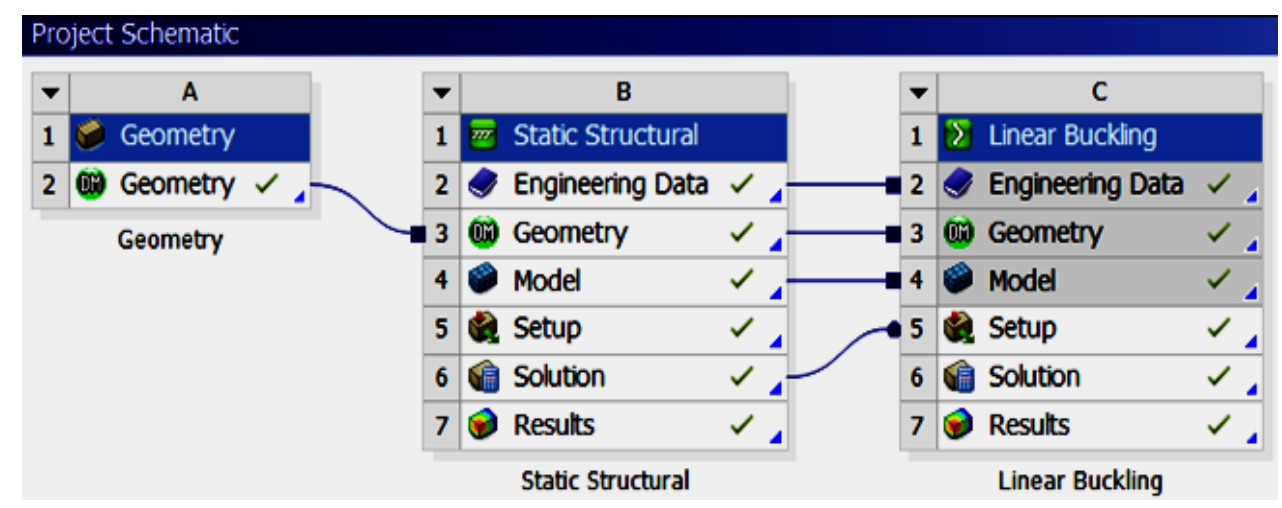

Figure-10. Buckling analysis.

\section{Results and Discussions}

The results of numerical analysis of the five MWCNT samples are shown in Figure-11. In this figure the buckling mode and the corresponding load multiplier (i.e: critical load) are shown for each fabricated sample. As it is clear from the Figure-11. The maximum value of critical load is at the sample with the highest weight ratio of Nano particles. The results of buckling loads of the five samples are collected in Table-2.

For the comparison purpose the experimental results of modulus of elasticity and critical load of buckling for the tested samples are collected in Table-2,also. The numerical and experimental results are plotted in Figure-12.As it is clear from Figure-12 that; the critical load of buckling is increased as the Nano to resin ratio increased and it becomes maximum at $2 \% \mathrm{wt}$ for both numerical and experimental cases .This behavior can be attributed to the increasing of the modulus of elasticity as the wt $\%$ of nano carbon increase (refer to Table-2). Figure-12 indicates fair agreements between the experimental and numerical analysis where the maximum error does not exceeded 15\%. These error may be due to many reasons such as; experimental error , difficulty to achieve perfect simply supported boundary condition in practice and computation errors. 


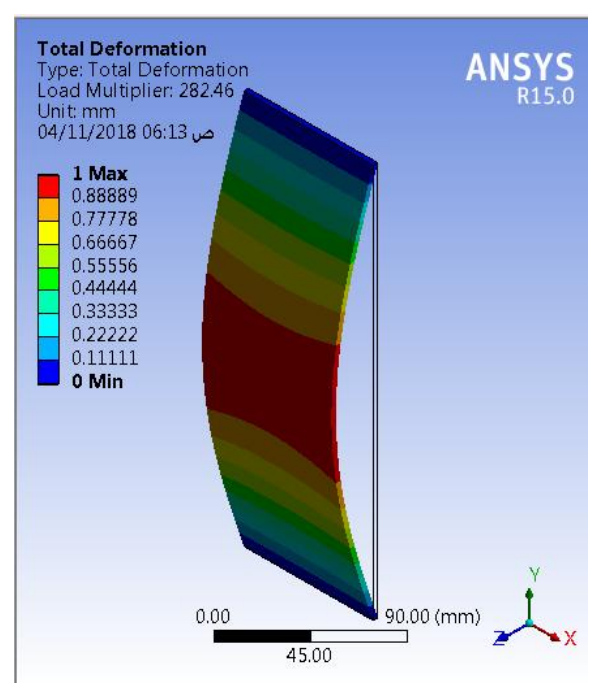

$0 \% \mathrm{wt}$

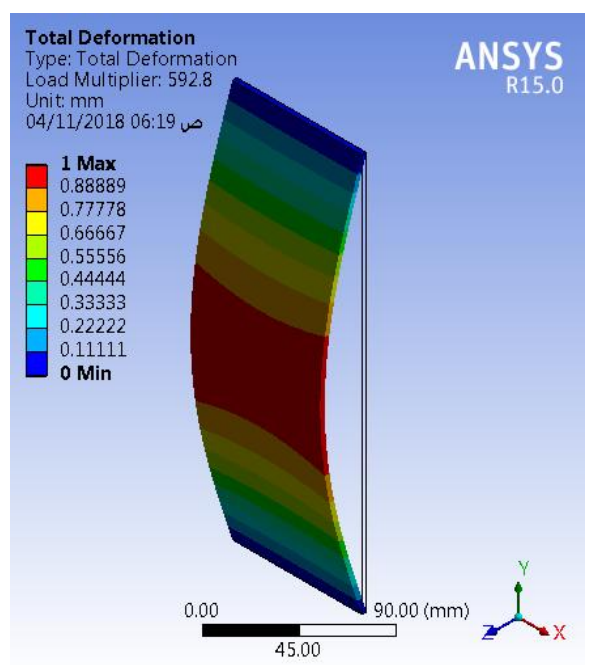

$1 \% \mathrm{wt}$

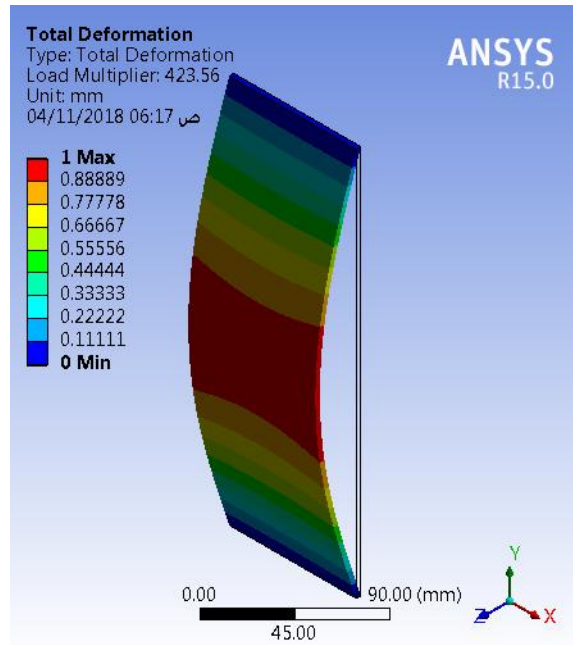

$0.5 \% \mathrm{wt}$

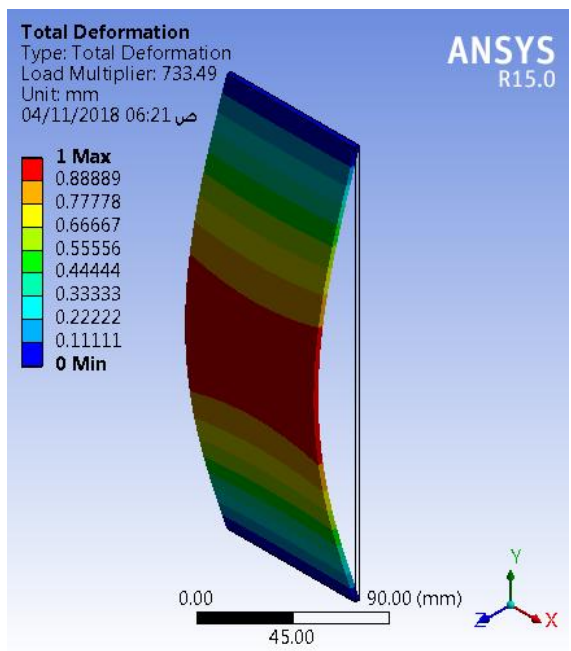

$1.5 \% \mathrm{wt}$

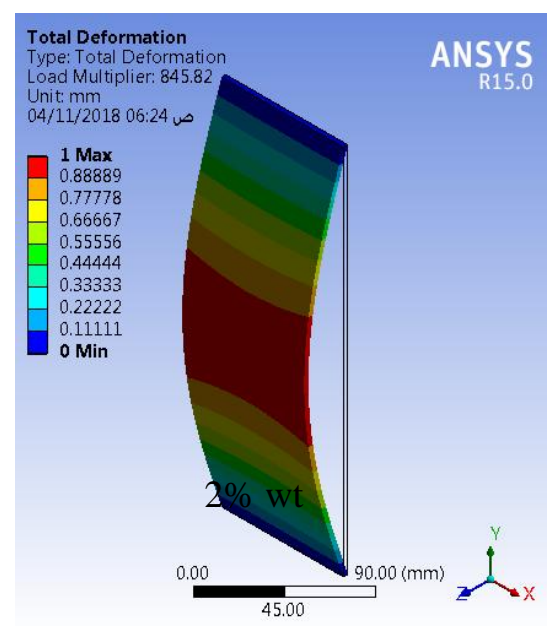

Figure-11. Buckling mode shape for samples with different wt $\%$. 
Table-2. Buckling loads and percentage error of the samples.

\begin{tabular}{|c|c|c|c|c|c|}
\hline \multirow{2}{*}{$\begin{array}{c}\text { Sample } \\
\text { NO. }\end{array}$} & \multirow{2}{*}{$\begin{array}{c}\text { \%Wt of } \\
\text { MWCNT }\end{array}$} & $\begin{array}{c}\text { Modulus of } \\
\text { Elasticity } \\
\mathbf{E}_{\mathbf{1}}=\mathbf{E}_{\mathbf{2}}(\mathbf{G p a})\end{array}$ & NUM. & Buckling Load (N) & \multirow{2}{*}{$\begin{array}{c}\text { Percentag } \\
\text { e error }\end{array}$} \\
\hline 1 & & 10 & 282.46 & 320 & $13 \%$ \\
\hline 2 & 0 & 15 & 423.56 & 485 & $14 \%$ \\
\hline 3 & 0.5 & 21 & 592.8 & 670 & $13 \%$ \\
\hline 4 & 1 & 26 & 733.49 & 830 & $13 \%$ \\
\hline 5 & 1.5 & 36 & 845.82 & 980 & $15 \%$ \\
\hline
\end{tabular}

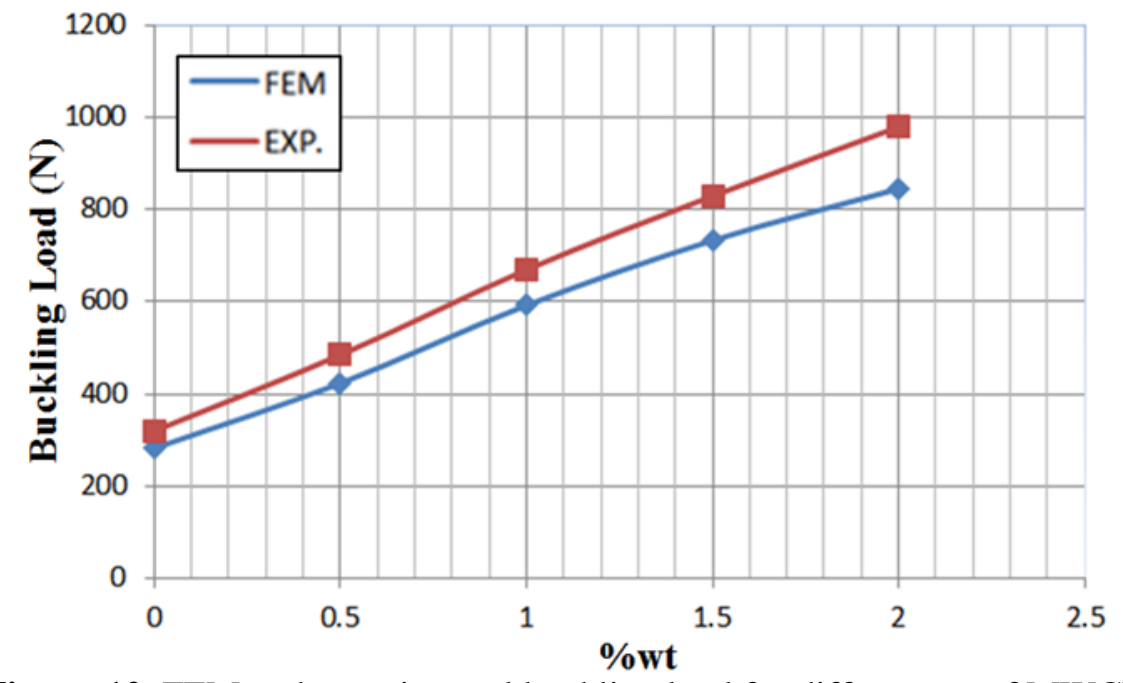

Figure-12. FEM and experimental buckling load for different wt of MWCNT

\section{Conclusions}

In this work the effect of adding nanotube carbon to composite material plates is investigated numerically and experimentally. From the discussions of the results the following conclusions can be derived; 1-The critical load of buckling instability increases as the weight ratio of Nano carbon tubes increase and the maximum value is at $2 \% \mathrm{wt}$.

2-The modulus of elasticity play the major role for improving buckling resistance in MWCNT plates.

3-In general the experimental results are in fair agreements with the numerical results where the percentage error is not exceeded $15 \%$.

\section{References}

[1] P. Kumar and J. Srinivas, "Vibration, buckling and bending behavior of functionally graded multiwalled carbon nanotube reinforced polymer composite plates using the layer-wise formulation," Composite Structures, vol. 177, pp. 158-170, 2017.

[2] R. Ansari, J. Torabi and M. F. Shojaei, "Buckling and vibration analysis of embedded functionally graded carbon nanotube-reinforced composite annular sector plates under thermal loading," Composites Part B, vol. 109, pp. 197-213, 2017. 
[3] P. T. Thang, T. Nguyen and J. Lee, "A new approach for nonlinear buckling analysis of imperfect functionally graded carbon nanotube-reinforced composite plates," Composites Part B, vol. 127, pp. 166-174, 2017.

[4] A. R. Setoodeh and M. Shojaee, "Critical buckling load optimization of functionally graded carbon nanotube-reinforced laminated composite quadrilateral plates," Polymer Composites, vol. 39, (S2), pp. E853-E868, 2018.

[5] H. R. Abdulshaheed, S. A. Binti, and I. I. Sadiq, "Proposed a Smart Solutions Based-on Cloud Computing and Wireless Sensing," Int. J. Pure Appl. Math., vol. 119, no. 18, pp. 427-449, 2018.

[6] K. Mackare and A. Jansone, "The concept for e-material creating and formatting application prototype,” Period. Eng. Nat. Sci., vol. 7, no. 1, pp. 197-204, 2019.

[7] N. Fantuzzi et al, "Free vibration analysis of arbitrarily shaped Functionally Graded Carbon Nanotube-reinforced plates," Composites Part B, vol. 115, pp. 384-408, 2017.

[8] E. García-Macías et al, "Buckling analysis of functionally graded carbon nanotube-reinforced curved panels under axial compression and shear," Composites Part B, vol. 108, pp. 243-256, 2017.

[9] A. Farzam and B. Hassani, "Thermal and mechanical buckling analysis of FG carbon nanotube reinforced composite plates using modified couple stress theory and isogeometric approach," Composite Structures, vol. 206, pp. 774-790, 2018.

[10] M. Ahmadi, R. Ansari and H. Rouhi, "Multi-scale bending, buckling and vibration analyses of carbon fiber/carbon nanotube-reinforced polymer nanocomposite plates with various shapes," Physica E: Low-Dimensional Systems and Nanostructures, vol. 93, pp. 17-25, 2017.

[11] N. George, P. Jeyaraj and S. M. Murigendrappa, "Buckling and Free Vibration of Nonuniformly Heated Functionally Graded Carbon Nanotube Reinforced Polymer Composite Plate," International Journal of Structural Stability and Dynamics, vol. 17, (6), pp. 1750064, 2017.

[12] C. Durakovic and A. Memon, "Potential of Algae for Biofuel Production," Period. Eng. Nat. Sci., vol. 4, no. 1, 2016.

[13] M. Wang, Z. Li and P. Qiao, "Vibration analysis of sandwich plates with carbon nanotubereinforced composite face-sheets," Composite Structures, vol. 200, pp. 799-809, 2018.

[14] Ö. Civalek and A. K. Baltacıŏglu, "Vibration of carbon nanotube reinforced composite (CNTRC) annular sector plates by discrete singular convolution method," Composite Structures, vol. 203, pp. 458-465, 2018. 